\title{
El proceso de unificación de la tutela civil de los derechos de propiedad intelectual en el Mercado Único Digital
}

\section{The unification process of civil guardianship of Copyright in the single digital market.}

FRANCISCO JAVIER MARTÍN ALÁEZ

Universidade da Coruña, Facultade de Dereito, Campus de Elviña, 15071 A Coruña, España

Francisco.javier.martin.alaez@udc.es

(c) $($ ) @ 9 Este artículo está sujeto a una licencia "Creative Commons ReconocimientoNo Comercial” (CC-BY-NC).

DOI: https://doi.org/ 10.24197/ree.79.2022.344-366

Resumen: Esta comunicación pretende proporcionar una primera valoración acerca de la protección que dispensa el Derecho de la Unión Europea frente al uso ilícito de obras protegidas por derechos de autor en Internet. El estudio pretende aportar resultados para la protección de los derechos de autor en el Mercado Único Digital a través del instrumento constituido por el Derecho de daños, como mecanismo de protección general de todos los derechos subjetivos e intereses jurídicamente protegidos.

Palabras clave: Propiedad intelectual, Mercado Único Digital, Responsabilidad civil, Prestación de servicios de intermediación en Internet, Plataformas en línea.

Abstract: This communication attempts to provide a first assessment of the protection supplied by European Union law against the illicit use of works protected by copyright on the Internet. The research aims to provide results for the protection of copyright in the Digital Single Market through the instrument constituted by the law of damages, as a general protection mechanism of all subjective rights and legally protected interests.

Keywords Copyright, Digital Single Market, Civil liability, Internet Service Providers, Online Platforms.

\section{INTRODUCCIÓN}

La evolución de las tecnologías digitales está permitiendo el incesante surgimiento de nuevos tipos de usos para que los consumidores puedan acceder a contenidos protegidos por derechos de autor, lo que determina 
que se produzcan desequilibrios entre los derechos e intereses de ambos que reclaman una adecuada respuesta desde la perspectiva jurídica. El mercado interior es uno de los logros más tangibles de la UE y el mercado único digital uno de sus corolarios en el que la protección de los derechos de propiedad intelectual adquiere una redoblada importancia. Es por ello que resulta necesario la creación de sistemas eficientes en toda la UE para la protección de dichos derechos.

1. LA ARMONIZACIÓN NORMATIVA PREVIA A LA DIRECTIVA 2019/790, DE 17 DE ABRIL, SOBRE DERECHOS DE AUTOR Y DERECHOS AFINES EN EL MERCADO ÚNICO DIGITAL (DDAMUD).

\subsection{La Directiva 2000/31/CE del Parlamento Europeo y del} Consejo, de 8 de junio de 2000, relativa a determinados aspectos jurídicos de los servicios de la sociedad de la información, en particular el comercio electrónico en el mercado interior (Directiva sobre el comercio electrónico) (DCE).

La DCE surge con la pretensión de lograr una armonización a nivel europeo de la normativa sobre responsabilidad relativa a los servicios de la sociedad de la información. Para ello sigue el esquema previsto en los Estados Unidos, pero con un marcado carácter de horizontalidad que abarca todo tipo de responsabilidades en juego, sea civil, penal o administrativa. El legislador europeo no pretendió tanto establecer un régimen de responsabilidad de los Prestadores de Servicios de la Sociedad de la Información («PSSI»), cuanto garantizarles una zona de exención de responsabilidad que permitiera superar la inseguridad jurídica que sufrían los PSSI derivada de las disparidades de regulación existentes entre los distintos Estados miembros ${ }^{1}$.

Dentro de los PSSI podemos distinguir los Prestadores de Servicios de Internet («ISP») de otros Prestadores de Servicios de la Sociedad de la Información. A su vez dentro de los ISP nos interesa distinguir entre Prestadores de Servicios Intermediarios de Internet («PSII») de los

\footnotetext{
${ }^{1}$ Cfr. Rogel Vide, C. y Ortego Ruiz, M. (2015), Prestadores de servicios de internet y alojamiento de contenidos ilícitos. Editorial Reus. Madrid. Disponible en https://elibro-net.accedys.udc.es/es/lc/bibliotecaudc/titulos/46637.
} 
Proveedores de Contenidos ${ }^{2}$. Esta clasificación es importante porque la DCE sitúa a los PSII en un espacio de exoneración de responsabilidad («puerto seguro»).

Los PSII que la DCE incluye en su puerto seguro son los operadores de redes y proveedores de acceso («mere Conduit» o «mera transmisión»), los prestadores de servicios que realizan copia temporal de los datos solicitados por los usuarios («caching» o memoria «tampón») y los prestadores de servicios de almacenamiento o alojamiento de datos («hosting»). La DCE no incluye dentro de su puerto seguro a los prestadores de servicios que faciliten enlaces a contenidos o instrumentos de búsqueda, aunque sí prevé ${ }^{3}$ que en el futuro se puedan presentar propuestas de adaptación de la norma relativas a la responsabilidad de proveedores de hipervínculos y servicios de instrumentos de localización.

\subsection{La Directiva 2001/29/CE del Parlamento Europeo y del Consejo, de 22 de mayo de 2001, relativa a la armonización de determinados aspectos de los derechos de autor y derechos afines a los derechos de autor en la sociedad de la información (DDASI).}

El mercado único digital no puede suponer un obstáculo a la protección de los autores y demás titulares de derechos de propiedad intelectual. Toda armonización de los derechos de autor y derechos afines a los derechos de autor debe basarse en un elevado nivel de protección, dado que tales derechos son primordiales para la creación intelectual ${ }^{4}, \mathrm{y}$ a ese objetivo se encamina la DDASI.

La Directiva trata de superar la inseguridad jurídica que existe en relación con la protección de obras protegidas por derechos de autor en la red, y para ello otorga a todos los titulares de derechos reconocidos por la Directiva un derecho exclusivo de poner a disposición del público obras protegidas por derechos de autor ${ }^{5}$.

\footnotetext{
${ }^{2}$ Cfr. Rogel Vide, C. y Ortego Ruiz, M. (2015), «Prestadores de servicios de internet ...», op. cit.

${ }^{3}$ Cfr. artículo 21.2 DCE.

${ }^{4}$ Considerando 9 DDASI.

${ }^{5}$ Considerando 25 DDASI.
} 
Pero además es una norma fundamental en el proceso de unificación en cuanto que los derechos que contempla y sus excepciones y limitaciones han sido objeto de interpretación constante por la jurisprudencia del Tribunal de Justicia de la Unión Europea (en adelante TJUE), dando lugar a un elaborado régimen jurídico ${ }^{6}$ que, como se expondrá, constituye la base de un auténtico proceso unificador. De hecho, el Tribunal de Justicia ha declarado la importancia de la Directiva 2001/29 a la hora de definir los conceptos autónomos y ha consagrado el "elevado nivel de protección a favor de los autores" como principio general que debe tenerse en cuenta al interpretar todas las directivas que pretenden armonizar los diferentes aspectos del derecho de autor.

\subsection{La Directiva 2004/48/CE, del Parlamento europeo y del Consejo, de 29 de abril, relativa al respeto de los derechos de propiedad intelectual (DRDPI).}

La tutela de la propiedad intelectual es esencial para el funcionamiento del mercado único digital, su protección debe asegurar una retribución adecuada y un beneficio legítimo al inventor o creador y garantizar una amplia difusión de las obras, ideas y los conocimientos, pero sin constituir un obstáculo al respeto de Derechos Fundamentales como la libertad de expresión o la libre circulación de la información ni a la protección de los datos personales.

La DRDPI vela por la protección de los consumidores y protege a los autores mediante un conjunto mínimo de medidas, procedimientos y recursos que permiten ejercitar procedimientos civiles efectivos para garantizar el respeto de los derechos de propiedad intelectual en toda la Unión Europea ${ }^{7}$. Supone un paso adelante de la Unión "para garantizar un nivel de protección de la propiedad intelectual elevado, equivalente y

\footnotetext{
${ }^{6}$ Llopis Nadal, P. (2018), “Enlaces en Internet y derechos de Propiedad Intelectual”. Revista de derecho y nuevas tecnologías 48. pp. RR 4.1 - RR 4.21. Disponible en https://proview.thomsonreuters.com/launchapp/title/aranz/periodical/106943754/v20 180048/page/RR-4.1.

${ }^{7}$ Comisión Europea (2017): «Directrices sobre determinados aspectos de la Directiva 2004/48/CE del Parlamento Europeo y del Consejo, relativa al respeto de los derechos de propiedad intelectual», disponible en https://eur-lex.europa.eu/legalcontent/ES/TXT/?uri=CELEX:52017DC0708.
} 


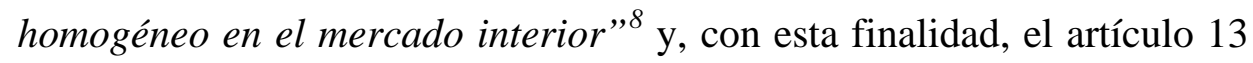
contempla la acción indemnizatoria por los daños derivados de la infracción de los derechos de propiedad intelectual.

Sin embargo, la práctica demuestra que la regulación de la DRDPI, basada en una armonización de mínimos, no amparaba la reparación adecuada en los casos de vulneración de los derechos de propiedad intelectual y originaba inseguridad jurídica dentro del Mercado Único Digital en el que este tipo de obras que se mueven: "las medidas, los procedimientos y los recursos (...) no se ejecutan ni se aplican de manera uniforme entre los Estados miembros", lo que provoca "diferentes interpretaciones relacionadas con su alcance (...) o cálculos de daños”. La evaluación de los daños y perjuicios por infracción de los derechos de autor resulta complicada en la práctica y "los titulares de derechos, la judicatura, los profesionales del Derecho y los ciudadanos han pedido mayor claridad jurídica sobre el cálculo de los daños (...)" 9 . Como en ocasiones anteriores, ha sido el Tribunal de Justicia de la Unión Europea el que ha tenido que abordar la interpretación del artículo 13 de la DRDPI en sus sentencias de 17 de marzo de 2016 (C-99/15, asunto Liffers) y de 25 de enero de 2017 (C-367/15, asunto Stowarzyszenie), unificando su sentido y alcance.

\section{LA DIRECTIVA 2019/790, DE 17 DE ABRIL, SOBRE DERECHOS DE} AUTOR Y DERECHOS AFINES EN EL MERCADO ÚNICO DIGITAL.

\subsection{El uso de contenidos protegidos por parte de prestadores de servicios para compartir contenidos en línea.}

El artículo 17 de la DDAMUD contiene un elemento unificador al incorporar una regla de exoneración de responsabilidad por infracción directa en favor de los «prestadores de servicios para compartir contenidos en línea» ${ }^{10}$ que modifica el marco jurídico en el que se venían

\footnotetext{
${ }^{8}$ Considerando 10 DRDPI.

${ }^{9}$ Cfr. Comisión Europea (2017): «Directrices...», op. cit.

${ }^{10}$ Peguera Poch, M. (2018): "La exoneración de responsabilidad por infracción directa en la Directiva de derechos de autor en el mercado único digital”. Actas de Derecho Industrial y Derecho de Autor 39, pp. 229-249.
} 
desenvolviendo las plataformas desde la $\mathrm{DCE}^{11}$ al ordenar a los Estados miembros que dispongan que "los prestadores de servicios para compartir contenidos en línea realizan un acto de comunicación al público o de puesta a disposición del público a efectos de la presente Directiva cuando ofrecen al público el acceso a obras protegidas por derechos de autor $u$ otras prestaciones protegidas que hayan sido cargadas por sus usuarios” (art. 17.1 DDAMUD).

La Directiva define a estos prestadores en el artículo 2.6) como «un servicio de la sociedad de la información cuyo fin principal, o uno de cuyos fines principales, es almacenar y dar al público acceso a una gran cantidad de obras u otras prestaciones protegidas cargadas por sus usuarios, que el servicio organiza y promociona con fines lucrativos». Por tanto, no se refiere a los tradicionales servicios de hosting, que continuarán bajo el puerto seguro de la DCE, a menos que cumplan las condiciones del artículo 2.6).

\subsection{La exclusión del puerto seguro de la DCE}

A efectos de la Directiva estos prestadores realizan un acto de comunicación al público o de puesta a disposición del público y son responsables por ello, por lo que, cuando concurran las situaciones que el propio artículo contempla, no se aplicará «la limitación de responsabilidad prevista en el artículo 14, apartado 1, de la Directiva 2000/31/CE», y configura para ellos un nuevo espacio de exención de responsabilidad de carácter vertical, con un alcance limitado al campo de la propiedad intelectual y de características distintas.

\subsection{El nuevo puerto seguro de la DDAMUD.}

Teniendo en cuenta que los contenidos no son cargados por ellos sino por sus usuarios, la DDAMUD ofrece a los prestadores de servicios para

${ }^{11}$ Vid. entre otros, López Richart, J. (2019): "Responsables, ma non troppo. Las reglas de exención de responsabilidad de las plataformas para el intercambio de contenidos en línea en la directiva sobre derechos de autor en el mercado único digital”. En Saiz García, C. (dir.) y Evangelio Llorca, R. (dir.), Propiedad intelectual y mercado único digital europeo, pp. 307- 366. 
compartir contenidos en línea la posibilidad de beneficiarse de una exención de responsabilidad que les protege exclusivamente frente a la responsabilidad derivada de la realización de actos de comunicación y puesta a disposición del público cuando demuestren haber desplegado la máxima diligencia exigible para evitar el daño, siguiendo un esquema que recuerda a la excepción de diligencia prevista en sistemas de responsabilidad por riesgo o responsabilidad objetiva atenuada ${ }^{12}$.

Los supuestos en los que no se les podrá exigir responsabilidad se concreta en tres obligaciones que el proveedor deberá probar que ha cumplido acumulativamente: en primer lugar, que ha hecho los mayores esfuerzos para obtener una autorización, lo que también supone el reconocimiento de que los titulares de derechos no están obligados a otorgar una autorización ${ }^{13}$; en segundo lugar, que han hecho, de acuerdo con normas sectoriales estrictas de diligencia profesional, los mayores esfuerzos por garantizar la indisponibilidad de obras y otras prestaciones específicas respecto de las cuales los titulares de derechos les hayan facilitado la información pertinente y necesaria (art. 17.4.b DDAMUD). Como señala la doctrina, en la práctica este requisito se traduce en la obligación de establecer técnicas de filtrado previo y reconocimiento automático de contenidos que identifiquen aquellos que los usuarios intentan subir a la plataforma y sean coincidentes con obras o prestaciones protegidas. En tercer lugar, deberán acreditar que han actuado de modo expeditivo al recibir una notificación suficientemente motivada de los titulares de derechos, para inhabilitar el acceso a las obras u otras prestaciones notificadas o para retirarlas de sus sitios web, y han hecho los mayores esfuerzos por evitar que se carguen en el futuro (art. 17.4.c DDAMUD), de conformidad con lo que se ha señalado en la segunda obligación. Para Peguera Poch el supuesto de hecho parece referirse a contenidos no autorizados, respecto de los cuales el proveedor no recibió la información pertinente y necesaria para evitar su subida a la plataforma; o bien a casos en que, a pesar de haber recibido aquella

${ }^{12}$ Cfr. Peguera Poch, M. (2018): «La exoneración de responsabilidad ...», op. cit., pág. 241.

${ }^{13}$ Cfr. Peguera Poch, M. (2018): «La exoneración de responsabilidad ...», op. cit., pág. 241. 
información y de la diligencia observada por el proveedor, el contenido logró escapar al filtro ${ }^{14}$.

\subsection{El régimen especial aplicable a las startups y empresas emergentes.}

La DDAMUD suaviza estas obligaciones para que los nuevos prestadores de servicios para compartir contenidos en línea cuyos servicios lleven menos de tres años a disposición del público en la Unión y cuyo volumen de negocios anual sea inferior a $10.000 .000 €$ puedan acogerse al nuevo puerto seguro y no tengan que cumplir con las obligaciones relativas al filtrado previo y reconocimiento automático de contenidos (art. 17.6 DDAMUD). Esto supone que tampoco estén obligados a hacer todo lo posible para asegurar que no están disponibles en la plataforma los contenidos protegidos sobre los que han recibido la necesaria información ni a realizar los mayores esfuerzos para impedir que los contenidos retirados tras una notificación se vuelvan a subir a la web $^{15}$, salvo que el promedio de visitantes únicos mensuales de la plataforma exceda de cinco millones (art. 16.6, pf. $2^{\circ}$, DDAMUD).

Pero una vez transcurridos tres años de servicios en la Unión les será de aplicación el régimen general, aunque la dimensión de la plataforma continuará constituyendo un elemento que se tendrá en cuenta a la hora de valorar el cumplimiento de las obligaciones impuestas por el nuevo puerto seguro de la DDMUD.

\section{LA LABOR UNIFICADORA DE LA JURISPRUDENCIA DEL TJUE.}

\subsection{La acción indemnizatoria del artículo 13 DRDPI.}

La indemnización contemplada en este artículo comprende tanto el valor de la pérdida sufrida por el titular del derecho infringido (daño emergente), como la ganancia que este haya dejado de obtener como

${ }^{14}$ Cfr. Peguera Poch, M. (2018): «La exoneración de responsabilidad ...», op. cit., pág. 242.

${ }^{15}$ Cfr. Peguera Poch, M., (2018): «La exoneración de responsabilidad ...», op. cit., pág. 243. 
consecuencia de la infracción (lucro cesante). Prevé, además, la indemnización del daño moral, si bien asociada de manera exclusiva a uno de los modos de fijación de la indemnización por lucro cesante, dentro de la letra a) de su apartado 1 .

\subsubsection{La regalía hipotética y los daños patrimoniales.}

\subsubsection{En el daño emergente.}

El daño emergente hace alusión a aquellos daños patrimoniales efectivamente producidos. Se trata de uno de los dos elementos o partidas clásicas del daño indemnizable, de acuerdo con los principios generales del derecho de daños y la doctrina lo considera implícito en la expresión «consecuencias económicas negativas» de apartado 1 a) del artículo $13^{16}$. El daño emergente es compatible (y acumulable) con el criterio de fijación del quantum del lucro cesante, a elección del perjudicado, pero resulta más dudosa su acumulación al importe de la regalía hipotética establecida en la letra b).

El TJUE en su Sentencia de 25 de enero de 2017 (asunto C-367/15) ha unificado este extremo al afirmar que «el mero pago, en el supuesto de una vulneración de un derecho de propiedad intelectual, del canon hipotético no puede garantizar una indemnización de todo el perjuicio realmente sufrido, dado que el pago de ese canon, por sí solo, no garantiza ni el reembolso de los eventuales gastos vinculados a la investigación de posibles infracciones, evocados en el Considerando 26 de la Directiva 2004/48, ni la indemnización de un posible daño moral (vid, a este último respecto, la Sentencia de 17 de marzo de 2016, Liffers, C-99/15, apartado 26), ni tampoco el pago de intereses de las cantidades adeudadas» (apartado 30 de la Sentencia).

\footnotetext{
${ }^{16}$ Moralejo Imbernón, N., (2017): "La indemnización de daños en caso de infracción de los derechos de propiedad intelectual”. Actas de Derecho Industrial y Derecho de Autor, 38, p. 335.
} 


\subsubsection{En el lucro cesante.}

El lucro cesante es la ganancia que el titular de los derechos ha dejado de obtener por su explotación debido a la intromisión de un tercero, esto es, por la utilización ilícita (o no autorizada) de su obra o prestación llevada a cabo por otra persona ${ }^{17}$. Ante la infracción de derechos de propiedad intelectual el artículo 13 DRDPI permite al perjudicado reclamar, además del daño emergente, el lucro cesante, pudiendo optar por cualquiera de estos tres métodos de cálculo del daño:

- los beneficios que previsiblemente hubiera obtenido el titular de los derechos si no hubiera existido la competencia del infractor (lucro cesante tradicional).

- los beneficios obtenidos por el infractor con la injerencia en el derecho ajeno (lucro de intervención).

- una remuneración equivalente al valor de cesión del derecho en el mercado (daño regalía).

En caso de infracción de los derechos de propiedad intelectual, la Ley posibilita que el perjudicado opte a una valoración abstracta del daño (regalía hipotética) a la que podrá acogerse, aunque se hubiera acreditado que nunca hubiera concedido una licencia, y no requiere prueba de que de la infracción se hubieran derivado daños concretos. Esta es la postura que sostiene el TJUE en la Sentencia de 25 enero $2017^{18}$, al afirmar que "el artículo 13 de la Directiva 2004/48 debe interpretarse en el sentido de que no se opone a una normativa nacional, como la controvertida en el litigio principal, con arreglo a la cual el titular de un derecho de propiedad intelectual vulnerado puede solicitar a la persona que ha vulnerado dicho derecho, bien la reparación del perjuicio sufrido, tomando en consideración todos los aspectos pertinentes del caso de que se trate, bien, sin que ese titular tenga que demostrar el perjuicio efectivo, el pago de una cantidad correspondiente al doble de la remuneración adecuada que se habría debido abonar por la autorización para utilizar la obra afectada". Incluso procederá en el supuesto de que

${ }^{17}$ Cfr. Moralejo Imbernón, N., (2017): «La indemnización...», op. cit., pág. 355.
${ }^{18}$ Sentencia Stowarzyszenie, C-367/15, apartado 33. 
hubiera obtenido un beneficio por la utilización ilícita de la obra o prestación ajenas como sucedió en el caso Ariston que dio lugar a la teoría de la Shadensberechnung ${ }^{19}$.

Cuestión distinta es la posible compatibilidad entre la acción indemnizatoria y la acción de enriquecimiento injustificado. En este sentido podemos destacar la propuesta ofrecida por Busto Lago para quien "la subsidiariedad de la acción de enriquecimiento no puede predicarse con carácter general, de forma que si concurren los presupuestos habilitantes del ejercicio de otras acciones concurrentes, éstas y aquélla podrán ser ejercitadas bien de forma alternativa, a elección del titular de las mismas, bien de forma sucesiva, respetando en todo caso, lógicamente, el régimen jurídico propio de cada una de ellas y en particular los distintos plazos de prescripción a los que estén sometidas dichas acciones" ${ }^{20}$.

\subsubsection{La regalía hipotética y el daño moral.}

Al daño moral se refiere el apartado a) del artículo 13.1. DRDPI al contemplar los dos primeros métodos de cálculo del daño. La Directiva establece la opción por el daño regalía en el apartado b), por lo que parece que desvincula el daño moral de la indemnización basada en la regalía. El TJUE en la Sentencia de 17 de marzo de $2016^{21}$ resolvió la discusión al establecer que "el artículo 13, apartado 1, de la Directiva 2004/48 debe interpretarse en el sentido de que permite al perjudicado por la violación de su derecho de propiedad intelectual que reclama una indemnización del daño patrimonial calculada, (...), sobre la base de licencias hipotéticas reclamar además la indemnización del daño moral".

${ }^{19}$ Cfr. Moralejo Imbernón, N. (2017): «La indemnización...», op. cit. pág. 365.

20 Busto Lago, J. M., y Peña López, F. (1997): "Enriquecimiento injusto y responsabilidad civil extracontractual”, Anuario da Facultade de Dereito da Universidade da Coruña 1, pp. 141-166, disponible en http://hdl.handle.net/2183/1921.

${ }^{21}$ Sentencia Liffers, C-99/15, apartado 27. 


\subsection{La responsabilidad de los prestadores de servicios de la sociedad de la información que facilitan enlaces a obras o prestaciones protegidas}

La DCE no incluyó inicialmente dentro de su puerto seguro a los prestadores de servicios que facilitan enlaces a contenidos o instrumentos de búsqueda, lo que ha motivado que se discutiese su responsabilidad cuando dirigen a obras o prestaciones protegidas por derechos de autor.

3.2.1 La cuestión de la responsabilidad de los PSSI que facilitan enlaces a obras o prestaciones protegidas.

Sea cual sea el modelo utilizado para la explotación -disfrute en línea, descarga directa o intercambio $\mathrm{P} 2 \mathrm{P}-$, el principal problema al que se enfrentan los PSSI que facilitan enlaces a obras o prestaciones protegidas es el de su posible responsabilidad cuando los titulares de derechos no han otorgado su consentimiento. Y ello, con independencia de la posible responsabilidad directa del proveedor de contenidos o del internauta que accede a la obra.

Como ha señalado el TJUE, lo determinante es si se produce una puesta a disposición o una transmisión cubierta por el derecho de autor, y esto no sucede cuando el enlace se limita a remitir a una página que sí permite acceder al contenido, sin dar acceso a la concreta obra o prestación. Por el contrario, si el enlace pone a disposición un contenido protegido determinado se planteará la posible responsabilidad del enlazador.

En los intercambios P2P no ofrece duda que la intervención de los enlazadores es crucial en cuanto que el éxito de estas redes depende de que se puedan localizar pares disponibles para el intercambio y descarga de las obras buscadas, lo que resultaría muy complicado sin la intervención de los prestadores ${ }^{22}$. Más problemática puede resultar su papel en el disfrute en línea y la descarga directa, pudiéndose discutir su responsabilidad cuando el enlace dirige directamente obras 0 prestaciones protegidas. Como los contenidos se encuentran alojados en un sitio distinto a la web del enlazador, la puesta a disposición inicial de

${ }^{22}$ Conclusiones Stichting Brein II, C-610/15, apartado 26. 
la obra no la realiza este sino el proveedor de contenidos, por lo que podría afirmarse que aquellos no realizan un acto de comunicación pública. No obstante, nada impediría que el enlazador pudiese ser considerado responsable indirecto por la infracción de los derechos de propiedad intelectual si se interpreta que colabora en la explotación ${ }^{23}$.

Lo que sucede es que el derecho de daños no está armonizado a nivel de la Unión ${ }^{24}$, lo que implica que cada Estado aplique sus propias normas internas para atribuir responsabilidad. Así, mientras que para algunos Estados miembros las actividades de los PSII que se describen en el puerto seguro se consideran supuestos que pueden generar responsabilidad indirecta por la participación en la conducta ilícita de un tercero, para otros esa conducta es constitutiva de una actuación negligente por incumplimiento del deber de cuidado o de la obligación de no causar daño a tercero, por lo que podría dar lugar a una responsabilidad por hecho propio ${ }^{25}$. Así, si considerásemos que la DCE limita la exclusión a los casos en que la responsabilidad pueda calificarse como derivada de hecho ajeno, en esos ordenamientos jurídicos el intermediario no quedaría cubierto por el puerto seguro aun cuando no haya cometido una infracción directa de los derechos de propiedad intelectual $^{26}$.

Pues bien, el TJUE ha encontrado en la falta de armonización de la responsabilidad indirecta por la infracción de los derechos de propiedad intelectual dentro de la Unión ${ }^{27}$ un argumento más para continuar con su labor unificadora, y así, al ir interpretando el artículo 3.1 de la DDASI en los distintos asuntos que ha tenido la oportunidad de conocer, ha ido

${ }^{23}$ Llopis Nadal, P. (2018): «Enlaces en Internet ...», op. cit. pág. RR-4.7.

24 Vid. Rubí Puig, A. y Ramírez Silva, P. (2018): "El nuevo derecho de acceso. (Evolución de la jurisprudencia del TJUE en materia de comunicación al público en relación con las actividades que facilitan el acceso a obras protegidas)”. Pe.i 58, pp. 13-86.

25 Angelopoulos, C.J. (2016): European Intermediary Liability in Copyright. A TortBased Analysis, Kluwer Law Intemational, pp. 145-387.

${ }^{26}$ Peguera Poch, M., (2018), "La exoneración de responsabilidad por infracción directa en la Directiva de derechos de autor en el mercado único digital”. Actas de derecho industrial y derecho de autor 39, p. 238.

27 Angelopoulos, C.J. (2016): «European Intermediary Liability in Copyright ...», op. cit., pp. 145-387. 
desarrollado el concepto autónomo de comunicación al público, considerando por una parte que, en determinados supuestos, la actividad de los enlazadores puede constituir un acto de puesta a disposición y, por otra, extendiendo el concepto a otras actividades relacionadas con los enlaces, lo que puede suponer de facto considerarlos responsables directos en caso de infracción de los derechos de propiedad intelectual ${ }^{28}$.

\subsubsection{Los pronunciamientos del TJUE sobre enlaces a obras protegidas.}

Las distintas cuestiones prejudiciales que se han planteado ante el TJUE han evidenciado la problemática que provoca el empleo de enlaces para facilitar el acceso a obras y prestaciones protegidas por derechos de propiedad intelectual. Con cada pronunciamiento el Tribunal ha perfeccionado el régimen jurídico de los enlazadores en relación con los derechos de propiedad intelectual, aclarando en qué supuestos se puede incurrir en responsabilidad directa por infracción de los derechos de propiedad intelectual cuando se facilitan enlaces a contenidos protegidos, lo que se puede entender como un auténtico proceso unificador en la materia.

Las resoluciones del TJUE a las que nos referiremos son las Sentencias de los asuntos Svensson (C-466/12, EU:C:2014:76, de 13 de febrero de 2014.), GS Media (C-160/15, de 8 de septiembre de 2016), Stichting Brein I (C-527/15, de 26 de abril de 2017) y Stichting Brein II (C-610/15, de 14 de junio de 2017) en relación con el régimen jurídico de la responsabilidad de los prestadores de servicios que faciliten enlaces a contenidos o instrumentos de búsqueda; y la Ordonnance BestWater (C348/13, de 21 octubre 2014) y la Sentencia del asunto VG Bild-Kunst (C392/19, de 9 de marzo de 2021), en relación con el régimen jurídico específico de la responsabilidad derivada del empleo de la técnica del framing.

\subsubsection{El asunto «Svensson»}

${ }^{28}$ Llopis Nadal, P. (2018), «Enlaces en Internet ...», op. cit., pág. RR-4.7. 
El Tribunal considera que, a efectos del artículo 3.1 DDASI, no constituye un acto de comunicación pública el hecho de proporcionar enlaces que conducen a obras que pueden consultarse libremente en otra página de Internet y señala dos requisitos que deben concurrir para que pueda entenderse que hay un acto de comunicación pública o de puesta a disposición del público: un acto de comunicación de una obra y la comunicación de esta a un público. Para que la obra sea comunicada efectivamente a un público el Tribunal considera preciso además que, o bien se utilice un medio técnico específico diferente al empleado en la comunicación de origen ${ }^{29}$, o bien que la comunicación se dirija a un público nuevo, es decir, un público que no fue tomado en consideración por los titulares de los derechos de autor cuando autorizaron la comunicación inicial al público $^{30}$.

A continuación, da un paso más en su doctrina al señalar que la puesta a disposición de obras mediante enlaces no conduce tampoco a comunicar dichas obras a un público nuevo cuando el acceso a las obras en esa página no está sujeta a ninguna medida restrictiva y todos los internautas pueden consultarla libremente. Por el contrario, si los enlaces permitieran eludir las medidas de restricción adoptadas en la página en la que se encuentra la obra protegida, o dirigen a obras que ya no estuvieran a disposición del público en la página en la que se comunicó inicialmente o sólo lo estuvieran para un público limitado ${ }^{31}$, los usuarios de la página que gestiona los enlaces sí constituirían un público nuevo que no fue tomado en consideración por los titulares de los derechos de autor cuando autorizaron la comunicación inicial, de modo que esa nueva comunicación al público exigiría autorización de los titulares.

Svenson supone así un paso más en el proceso de unificación de la responsabilidad directa de los enlazadores llevada a cabo por la jurisprudencia del TJUE, que responderán directamente por actos propios cuando enlacen a contenidos protegidos sin perjuicio de la

\footnotetext{
${ }^{29}$ Vid. Sentencia ITV Broadcasting v TVCatchup C-607/11, de 7 de marzo de 2013, apartados 21 a 26.

${ }^{30}$ Sentencia Svensson, C-466/12, apartado 24.

${ }^{31}$ Sentencia Svensson, C-466/12, apartado 31.
} 
responsabilidad indirecta en que puedan incurrir respecto de actos que han sido cometidos por los usuarios de su servicio ${ }^{32}$.

\subsubsection{El asunto GS Media}

Es el asunto GS Media se plantea ante el TJUE un supuesto en que los enlaces conducen a obras cuya comunicación pública nunca había sido autorizada. En este asunto el Tribunal se refiere a la necesidad de realizar una apreciación individualizada en la que han de valorarse varios criterios complementarios, de naturaleza no autónoma y dependientes unos de otro. El primero es el papel ineludible del usuario, entendido como la imposibilidad de acceder a la obra sin la intervención del gestor, no bastando por tanto la mera dificultad para acceder a la obra. El segundo es el carácter deliberado de su intervención, entendido como conocimiento de las consecuencias de su comportamiento para dar a sus clientes acceso a una obra protegida ${ }^{33}$. Consciente de que la prueba de ese conocimiento puede resultar complicada en la práctica, el Tribunal crea una presunción de conocimiento en base a la concurrencia o no de ánimo de lucro, entendiendo que, cuando la colocación del hipervínculo la realiza una persona sin ánimo de lucro, no actúa, por lo general, con pleno conocimiento de las consecuencias de su comportamiento. Por otra parte, cuando la colocación de hipervínculos se efectúa con ánimo de lucro, cabe esperar que el enlazador realice las comprobaciones necesarias para asegurarse de que la obra de que se trate no se publica ilegalmente en el sitio al que lleven dichos hipervínculos, de modo que se ha de presumir que la colocación ha tenido lugar con pleno conocimiento de la naturaleza protegida de dicha obra y de la eventual falta de autorización de publicación en Internet por el titular de los derechos de autor. No obstante, se trata de una presunción iuris tantum que admite prueba en contrario ${ }^{34}$.

El problema que plantea esta interpretación del TJUE es que puede incentivar el establecimiento de plataformas 2.0 en las que son los propios usuarios quienes comparten los enlaces. Consciente de este

\footnotetext{
${ }^{32}$ Vid. Llopis Nadal, P. (2018): «Enlaces en Internet ...», op. cit., pág. RR-4.13.

${ }^{33}$ Sentencia GS Media, C-160/15, apartados 33 a 35.

${ }^{34}$ Sentencia GS Media, C-160/15, apartados 47 a 51.
} 
peligro, el TJUE trató de resolverlo en el asunto Stichting Brein II, al establecer que también se realiza una actividad susceptible de ser considerada como acto de comunicación pública cuando la plataforma gestione activamente y organice los enlaces.

A pesar de las numerosas críticas recibidas ${ }^{35}$, debe valorarse positivamente esta interpretación del TJUE en la medida que, al atribuirles responsabilidad directa por las infracciones cometidas como consecuencia de sus actos de comunicación pública de obras protegidas, ampara a los titulares de derechos frente a su uso ilegal en Internet, en cuanto que pueden actuar contra intermediarios situados en la Unión Europea que enlacen a contenidos protegidos alojados en terceros países, lo que permitirá obtener tanto el cese de los ilícitos como la indemnización por los daños y perjuicios causados conforme al artículo 13 de la DRDPI.

\subsubsection{Stichting Brein I}

En este asunto el Tribunal interpretó el art. 3.1 de la Directiva 2001/29 en el sentido de que el concepto comunicación al público también incluye actividades como la venta de reproductores multimedia con enlaces a páginas de Internet que alojan obras protegidas sin autorización cuando concurren el resto de los requisitos que hemos analizado supra.

Como señaló el abogado general en el apartado 51 de sus conclusiones, "no hay diferencias significativas entre colocar en un sitio web hipervínculos que remiten a obras protegidas y (...) colocarlos en un aparato multimedia concebido precisamente para su empleo en Internet”. Ambas actividades tienen en común la puesta a disposición del público de contenidos protegidos ${ }^{36}$.

\footnotetext{
35 Vid. entre otras, Conclusiones Stichting Brein I, C-527/15, de 8 de diciembre de 2016, apartado 71.

${ }^{36}$ Conclusiones Stichting Brein I, C-527/15, apartado 51.
} 


\subsubsection{Stichting Brein II}

En este pronunciamiento el Tribunal suple las carencias detectadas en la sentencia del asunto GS Media y estima que una plataforma de intercambio en la que son los usuarios actuando sin ánimo de lucro quienes facilitan los enlaces, podrá ser considerada infractora directa de los derechos de propiedad intelectual por realizar actos comunicación pública o de puesta a disposición del público si ofrece acceso a contenidos protegidos puestos a disposición del público sin autorización de su titular cuando los organiza y gestiona activamente, indexando metadatos relativos a las obras protegidas y proporcionando un motor de búsqueda que permitan a los usuarios de esa plataforma localizar dichas obras e intercambiarlas en una red entre pares (peer-to-peer) ${ }^{37}$.

\subsubsection{Los pronunciamientos del TJUE sobre la técnica del framing.}

El marco o framing es una técnica que permite insertar en una web obras o prestaciones protegidas que están alojadas en un sitio distinto. La obra no se reproduce en el servidor del sitio en el que se visualiza, sino que se consulta directamente a través de un enlace profundo sin que el usuario sea consciente de que éste procede de otro sitio $^{38}$. En la actualidad, el framing ha sido sustituido por el inline frame, que permite la inserción automática de recursos externos en el sitio web donde está ubicado el enlace sin que el usuario sea consciente de ello. El inline frame muestra la obra como un elemento integrante de esa página, al incrustar (embedding) recursos externos en una página web ${ }^{39}$.

\subsubsection{Ordonnance BestWater}

En el asunto Bestwater la controversia surgió por la publicación de un enlace ensamblado en una web (framing) que permitía visualizar un

${ }^{37}$ Sentencia Stichting Brein II, C-610/15, apartado 38 y fallo.

38 Conclusiones del Abogado General Sr. Maciej Szpunar presentadas el 10 de septiembre de 2020 en el Asunto C-392/19 VG Bild-Kunst (Apdo. 11).

${ }^{39}$ Vid. Conclusiones del Abogado General Sr. Maciej Szpunar, op. cit. (Apdo. 12); Vid. López Maza, S., (2021): “Framing y comunicación pública de contenidos protegidos por la propiedad intelectual”. La Ley Unión Europea 91, pág. 6/16. 
video de la plataforma Youtube cuya puesta a disposición los titulares de derechos sobre el mismo alegaron no haber consentido ${ }^{40}$.

El TJUE no llegó a pronunciarse sobre este tipo de enlaces al considerar que la cuestión ya había sido resuelta con la jurisprudencia Svensson, en la que, a propósito de la existencia o no de un público nuevo, sostuvo que su interpretación no sería distinta si el enlace fuera facilitado mediante la técnica del framing ${ }^{41}$.

\subsubsection{VG Bild-Kunst}

En marzo de 2021 el TJUE avanza en la unificación de la responsabilidad de los gestores de enlaces al reafirmar en VG Bild-Kunst la doctrina que establece que la provisión de enlaces que permitan eludir las medidas restrictivas a que están sometidas las obras enlazadas en el sitio web en el que están alojadas constituye un acto de comunicación pública sujeto a autorización, y dar un paso más al incluir dentro de ella las medidas tecnológicas que impidan el framing.

En este asunto, SPK, fundación alemana que gestiona una biblioteca digital, se niega a aplicar medidas destinadas a impedir el framing por parte de terceros de las obras en forma de miniaturas (thumbnails) a las que VG Bild-Kunst, entidad de gestión colectiva de los derechos de autor en el ámbito de las artes visuales en Alemania, supedita la celebración del contrato de uso de su repertorio. El Tribunal considera que la difusión de las imágenes en miniatura de obras protegidas constituye un acto de comunicación al público y que las medidas restrictivas del framing no restringen el acceso a las obras, sino el público de las obras a los usuarios del sitio de Internet de origen. Por tanto, si se han adoptado o impuesto la utilización de medidas restrictivas contra el framing, la inserción de una obra en la página web de un tercero utilizando la técnica del framing constituye una puesta a disposición de esa obra a un público nuevo y requiere autorización ${ }^{42}$.

\footnotetext{
${ }^{40}$ Ordonnance BestWater, C-348/13, apartado 4, in fine.

${ }^{41}$ Sentencia Svensson, C-466/12, apartado 29.

${ }^{42}$ Sentencia VG Bild-Kunst, C-392/19, apartado 48 y fallo.
} 


\section{FUTURAS NORMAS APLICABLES A LOS SERVICIOS Y A LAS PLATAFORMAS DIGITALES}

En diciembre de 2020 la Comisión propuso dos nuevas normas, una sobre servicios digitales y otra sobre mercados digitales, con el objetivo de regular servicios digitales como las redes sociales, los mercados en línea y otras plataformas en línea que operan en la Unión Europea.

En ocasiones las plataformas online pueden utilizarse indebidamente para difundir contenidos ilícitos o vender productos falsificados. Además, los derechos fundamentales de los ciudadanos europeos no están adecuadamente protegidos en línea y son frecuentes la merma a la libertad de expresión de los usuarios en Internet. Con el objeto de solucionar esos problemas se propone la Ley de Servicios Digitales, que promoverá una mejor protección de los consumidores y sus derechos fundamentales en línea. En otras ocasiones lo que sucede es que algunas grandes plataformas en línea actúan como «guardianes» en los mercados digitales y la Ley de Mercados Digitales tratará de garantizar que estas plataformas se comporten de manera equitativa en línea.

Lo destacable de estas dos nuevas iniciativas es que adoptarán la forma de Reglamento, por lo que una vez aprobadas serán directamente aplicable en toda la Unión. Al establecer obligaciones vinculantes a nivel de la UE a todos los servicios digitales que conecten a los consumidores con bienes, servicios o contenidos, nuevos procedimientos de retirada rápida de contenidos ilícitos y una protección completa de los derechos fundamentales de los usuarios en línea, la nueva normativa reequilibrará los derechos y las responsabilidades de los usuarios, plataformas intermediarias y autoridades públicas.

\section{CONCLUSIÓN}

La regulación vigente, basada en la Directiva de la UE, no resuelve satisfactoriamente la exigencia de una reparación adecuada en los casos de vulneración de los derechos de autor y la falta de armonización del Derecho de daños comporta que cada Estado pueda aplicar sus propias normas responsabilidad civil del infractor. Estas carencias normativas han motivado que el TJUE asumiese el impulso de un proceso de 
unificación en el ámbito de los derechos de propiedad intelectual en la que están presentes también algunos elementos del derecho de daños. Su actitud ha despertado, aunque de forma tímida, una corriente normativa unificadora en la UE. Así la DDAMUD, en su artículo 17, al unificar la responsabilidad directa de ciertos tipos de PSSI en relación con ciertas infracciones de los derechos de autor; también en el ámbito de los servicios digitales las nuevas propuestas normativas siguen esa tendencia unificadora de la responsabilidad en línea de las grandes plataformas. Estas serán directamente aplicables en toda la UE al adoptar forma de Reglamento y tendrán repercusiones en la protección de los derechos de autor, pero para la adecuada protección de los derechos e intereses legítimos (de los titulares de derechos de propiedad intelectual, pero también de los consumidores y usuarios) en el Mercado Único Digital a través del instrumento constituido por el Derecho de daños, sería deseable la adopción de una regulación específica que la afrontase.

\section{Bibliografía.}

Angelopoulos, C.J. (2016): European Intermediary Liability in Copyright. A Tort-Based Analysis. Kluwer Law International. The Netherlands. ISBN 978-90-411-6835-1.

Basozabal, X., (1997): "Método triple del cómputo del daño: la indemnización del lucro cesante en las leyes de protección industrial e intelectual”, Actas de Derecho Civil 50(3), pp. 1263-1300. Boletín Oficial del Estado. Madrid. ISSN 0210-301X.

Busto Lago, J. M., y Peña López, F. (1997): "Enriquecimiento injusto y responsabilidad civil extracontractual”. Anuario da Facultade de Dereito da Universidade da Coruña 1, pp. 141-166. Universidade da Coruña, Servicio de Publicacións. A Coruña. ISSN 1138-039X.

Comisión Europea (2017): "Directrices sobre determinados aspectos de la Directiva 2004/48/CE del Parlamento Europeo y del Consejo, 
relativa al respeto de los derechos de propiedad intelectual", disponible en https://eur-lex.europa.eu/legalcontent/ES/TXT/?uri=CELEX:52017DC0708.

De Miguel Asensio, P. (2021): "Servicios y mercados digitales: modernización del régimen de responsabilidad y nuevas obligaciones de los intermediarios”. La Ley Unión Europea 88. La Ley. Las Rozas (Madrid). ISSN 2255-551X.

López Maza, S. (2021): "Framing y comunicación pública de contenidos protegidos por la propiedad intelectual”. La Ley Unión Europea 91. La Ley. Las Rozas (Madrid). ISSN 2255-551X.

López Richart, J. (2019): "Responsables, ma non troppo. Las reglas de exención de responsabilidad de las plataformas para el intercambio de contenidos en línea en la directiva sobre derechos de autor en el mercado único digital”. En Saiz García, Concepción (dir.) y Evangelio Llorca, Raquel (dir.) Propiedad intelectual y mercado único digital europeo, pp. 366. Tirant lo Blanch. Valencia. ISSN 8413-365325.

Llopis Nadal, P. (2018): "Enlaces en Internet y derechos de Propiedad Intelectual". Revista de derecho y nuevas tecnologías 48, pp. RR 4.1 - RR 4.21. Editorial Aranzadi. Cizur Menor (Navarra). ISSN 16960351.

Moralejo Imbernón, N. (2017): “La indemnización de daños en caso de infracción de los derechos de propiedad intelectual". Actas de derecho industrial y derecho de autor 38, pp. 349-375. Marcial Pons. Madrid. ISSN 1139-3289.

Peguera Poch, M. (2018): "La exoneración de responsabilidad por infracción directa en la Directiva de derechos de autor en el mercado 
único digital”. Actas de derecho industrial y derecho de autor 39, pp. 229-249. Marcial Pons. Madrid. ISSN 1139-3289.

Rogel Vide, C. y Ortego Ruiz, M. (2015): Prestadores de servicios de internet y alojamiento de contenidos ilícitos. Editorial Reus. Madrid. ISBN 978-84-290-1885-1

Rubí Puig, A. y Ramirez Silva, P. (2018): "El nuevo derecho de acceso. (Evolución de la jurisprudencia del TJUE en materia de comunicación al público en relación con las actividades que facilitan el acceso a obras protegidas)”. Pe.i 58, pp. 13-86. Editorial Bercal. Madrid. ISSN 1576-3366.

Sánchez Aristi, R. (2019): “La Directiva (UE) 2019/790, de 17 de abril de 2019, sobre los derechos de autor y derechos afines en el Mercado Único Digital”. La ley mercantil 60. Editorial La Ley. Las Rozas (Madrid). ISSN 2341-4537. 